\title{
CLINICO-BACTERIOLOGICAL STUDY OF NEW LEPROSY CASES- AN EXPERIENCE AT A TERTIARY CARE CENTRE IN EASTERN NEPAL
}

\author{
Shraddha Siwakoti ${ }^{1}$, Narayan Raj Bhattarai ${ }^{2}$, Sudha Agrawal ${ }^{3}$, Abhilasha Sharma ${ }^{4}$, Basudha Khanal ${ }^{5}$
}

${ }^{1}$ Assistant Professor, Department of Microbiology, B. P. Koirala Institute of Health Sciences, Dharan, Nepal.

${ }^{2}$ Additional Professor, Department of Microbiology, B. P. Koirala Institute of Health Sciences, Dharan, Nepal.

${ }^{3}$ Professor, Department of Dermatology and STD, B. P. Koirala Institute of Health Sciences, Dharan, Nepal.

${ }^{4}$ Assistant Professor, Department of Microbiology, B. P. Koirala Institute of Health Sciences, Dharan, Nepal.

5 Professor and HOD, Department of Microbiology, B. P. Koirala Institute of Health Sciences, Dharan, Nepal.

\section{ABSTRACT}

\section{BACKGROUND}

Early detection of new cases is a major part of leprosy control programme. The diagnosis of leprosy is primarily clinical which is usually confirmed by demonstration of acid-fast bacilli (AFB) in slit-skin smear (SSS). There are very few studies on clinicobacteriological patterns of leprosy from Eastern Nepal at this post-elimination phase.

Aim- This study was performed to know the clinical profile of new leprosy patients attending this tertiary centre and to determine the significance of SSS in confirming clinically diagnosed leprosy.

\section{MATERIALS AND METHODS}

This is a descriptive prospective study. All consecutive, new clinically diagnosed leprosy cases at the Department of Dermatology of B.P. Koirala Institute of Health Sciences (BPKIHS) over a period of 12 months were included. Detailed history was taken and systemic examination was done. SSS were obtained from the patients and sent to Microbiology Department. Presence of AFB and BI was calculated using Ridley's logarithmic scale.

\section{RESULTS}

Borderline tuberculoid cases (BT) were the commonest types of leprosy 24 (48\%). There were total 3 (6\%) patients of paediatric age group. All the patients presented either with single type or mixed type of skin lesion. Nerve involvement was observed in 44 $(88 \%)$ patients with ulnar nerve $33(66 \%)$ being the commonest nerve. Grade 1 and grade 2 disability was found in 10 (20\%) and $6(12 \%)$ patients respectively. Skin smears were positive for AFB in 9 [18\%; 95\% CI, (9.54-31.02)] cases. Area under ROC curve of SSS is 0.906 .

\section{CONCLUSION}

Cases of BT leprosy are predominant. Presence of leprosy in paediatric age group indicates continued transmission. Notable disabilities were observed in our study. Although the slit-skin smear has low sensitivity, AUC of SSS was 0.906 indicating it being a good diagnostic tool. Being a simple and rapid method with high specificity, SSS can be used to confirm the diagnosis in clinically suspected patients of leprosy.

\section{KEYWORDS}

Leprosy, Clinical Examination, Slit-skin smear.

HOW TO CITE THIS ARTICLE: Siwakoti S, Bhattarai NR, Agrawal S, et al. Clinico-bacteriological study of new leprosy cases- An experience in at a tertiary care centre in Eastern Nepal. J. Evolution Med. Dent. Sci. 2017;6(48):3707-3710, DOI: $10.14260 /$ Jemds/2017/800

\section{BACKGROUND}

Leprosy is a chronic granulomatous disease caused by Mycobacterium leprae, an acid fast, rod shaped bacilli which eventually leads to disabilities if untreated. Although Nepal has achieved the leprosy elimination goal on 2010 at the national level, but sustaining the achievement and further reducing disease burden at the district level are still the major challenges. Early detection of new cases is a major part of leprosy control programme. ${ }^{1}$

Financial or Other, Competing Interest: None.

Submission 09-05-2017, Peer Review 02-06-2017,

Acceptance 08-06-2017, Published 15-06-2017.

Corresponding Author:

Dr. Shraddha Siwakoti,

Assistant Professor,

Department of Microbiology,

B. P. Koirala Institute of Health Sciences,

Dharan, Nepal.

E-mail: shraddha.siwakoti@bpkihs.edu

DOI: $10.14260 /$ jemds $/ 2017 / 800$
The diagnosis of leprosy is primarily clinical which is usually confirmed by demonstration of acid-fast bacilli (AFB) in slit-skin smear (SSS) by Ziehl-Neelsen (ZN) staining. ${ }^{2}$ The Ridley-Jopling (RJ) classification provides the optimal classification of leprosy disease spectrum which ranges from a form with a robust immune response and very few organisms (tuberculoid or paucibacillary) to a form with a weaker immune response and high burden of organisms (lepromatous or multibacillary). ${ }^{3}$ Likewise, the WHO classification system is based upon the number of skin lesions present, paucibacillary (PB) if five or fewer skin lesions without detectable bacilli on skin smears and multibacillary (MB) if six or more lesions and may be skin smear positive. ${ }^{4}$

SSS is a simple, rapid and cost effective conventional diagnostic tool for leprosy. In untreated patients, it helps in diagnosis of leprosy excluding clinical mimickers and for classification of leprosy within the RJ type and WHO type. Regardless of its low sensitivity, SSS remains gold standard for all diagnostic techniques due to its specificity of nearly $100 \% .^{5}$ The density of organisms in the smears is expressed 
as bacterial index (BI) which reflects the bacterial load of the patient. ${ }^{6}$ With regard to the drawbacks of SSS, WHO had recommended all smear-positive leprosy cases be treated as MB patients, ${ }^{4}$ which was later changed to a purely clinical classification with patients having $>5$ skin lesions considered as MB and $<5$ as PB.7 But, classifying leprosy only on basis of skin lesions may lead to over or under diagnosis with significant number of $\mathrm{MB}$ cases being treated with $\mathrm{PB}$ regimen. ${ }^{8}$ SSS still retains practical importance to sustain quality leprosy control services in this maintenance phase of leprosy elimination in Nepal. Therefore, this minimal invasive technique is preferred in different health centres of this region. This study was performed to know the clinical profile of new leprosy patients attending this tertiary centre and to determine the significance of SSS in confirming clinically diagnosed leprosy.

\section{MATERIALS AND METHODS \\ Study Design}

This is a descriptive prospective study.

\section{Study Area and Population}

All consecutive new clinically diagnosed leprosy cases at the Department of Dermatology of B. P Koirala Institute of Health Sciences (BPKIHS) over a period of 12 months from May 2012- April 2013 were included. Ethical clearance was obtained from institutional review board of BPKIHS, Dharan, Nepal. Patient who did not give consent and those patients who had received treatment for leprosy were excluded from the study. Detailed history was taken and systemic examination was done. Patients were clinically classified into tuberculoid (TT), borderline tuberculoid (BT), borderline (BB), borderline lepromatous (BL), and lepromatous (LL). ${ }^{3}$ Likewise, patients were also classified based on skin lesions into paucibacillary (PB) and multibacillary (MB). ${ }^{4}$

\section{Sampling Procedure and Processing}

SSS from six sites (two from earlobes, two from forehead just above the medial aspect of eyebrows, one from lesion and one from apparent normal skin) were obtained from each patient and sent to Microbiology Department. All the smears were stained by modified $\mathrm{ZN}$ staining ${ }^{9}$ and seen by a microbiologist. Presence of AFB and BI was calculated using Ridley's logarithmic scale ${ }^{10}$ by using at least 100 oil immersion field of smears. The BI from each patient was reported as an average BI value determined from SSS performed on six sites. The data were recorded in a predesigned proforma.

\section{Statistical Analysis}

SPSS Version 16.0. (Chicago, SPSS Inc.) was used for statistical analysis. Data were statistically described in terms of range, mean \pm standard deviation (SD), frequency (number of cases), relative frequency (percentages), and confidence interval when appropriate. In addition, the ROC curve was analysed for SSS by ROC Analysis (www.jrocfit.org). ${ }^{11}$

\section{RESULTS}

We studied 50 untreated cases of clinically proved leprosy.

\section{Demographic Features}

Patient's age ranged between 10-75 years with $42.12 \pm 17.11$ years being mean age of presentation. There were total 3 (6\%) patients of paediatric age group and none of them had family history of leprosy. There were 27 (54\%) male and 23 (46\%) female patients. History of contact with a leprosy patient was found in $11(22 \%)$ of patients.

\section{Clinical Features}

All the patients presented either with single type or mixed type of skin lesion. Skin lesions were erythematous in 33 (66\%), hypoaesthetic in 24 (48\%), hypopigmented in 18 $(36 \%)$ and anaesthetic in $7(14 \%)$. Plaque 39 (78\%), macule $17(34 \%)$ and nodule 7 (14\%) were the common types of skin lesions. Nerve involvement was observed in 44 (88\%) patients. Multiple nerve involvement was present in $5(10 \%)$ patients. There were $11(22 \%)$ patients with involvement of eye. Photophobia and lacrimation were the most common eye symptoms with $6(12 \%)$ each. As the disease progresses from tuberculoid end of spectrum to lepromatous end, patients develop deformities. Disability was found in 16 (32\%) patients and was further graded according to WHO protocol with grade 1 , ten $(20 \%)$ and grade 2 , six (12\%) patients. Characteristic features of advanced disease were also noted in some patients; loss of hair and sweating $6(12 \%)$, nasal stuffiness and epistaxis $4(8 \%)$ and orchitis $2(4 \%)$. (Table 1$)$. Clinically, cases were classified according to RJ classification: TT 1 (2\%), BT 24 (48\%), BB1 (2\%), BL14 (28\%), LL 9 (18\%) type. (Table 2). There was $1(2 \%)$ case of pure neuritic (PN) variety. All the 3 paediatric cases $(100 \%)$ were of BT variant of leprosy. Cases were also categorised according to WHO classification with 41 (82\%) MB type and 9 (18\%) PB.

\section{SSS}

Skin smears were positive for AFB in 9 [18\%; 95\%CI, (9.5431.02)] cases; BI ranged from $1+$ to $6+$. (Fig. 1) Amongst them, $6(67 \%)$ of LL and $2(14 \%)$ of BL patients were positive for AFB. There was only 1 case of BB in this study which also was AFB positive. All cases of TT and BT showed no AFB in skin smears. The BI in different types of leprosy in relation to $\mathrm{RJ}$ classification is shown in Table 2. Receiver Operating Characteristic (ROC) curve analysis was performed for SSS with RJ classification. Area under ROC curve of SSS is 0.906 . (Fig. 2). The SSS were positive in 9 (22\%) of the 41 WHO-MB cases whereas, none of the 9 WHO-PB cases were AFB positive. Correlation of report of SSS and WHO classification in diagnosing MB cases is shown in Table 3.

\begin{tabular}{|c|c|c|c|}
\hline Symptoms & & Number & $\mathbf{\%}$ \\
\hline Skin lesion & Anaesthesia/ & 50 & 100 \\
\hline & Hypoesthesia & 31 & 62 \\
\hline $\begin{array}{c}\text { Peripheral Nerve } \\
\text { Involvement }\end{array}$ & Ulnar nerve & 33 & 88 \\
\hline & Lateral Popliteal & 29 & 56 \\
\hline & Radial Cutaneous & 21 & 42 \\
\hline & Posterior Tibial & 16 & 32 \\
\hline & Radial nerve & 4 & 8 \\
\hline \multicolumn{2}{|c|}{} & 11 & 22 \\
\hline Eye involvement & & 16 & 35 \\
\hline \multicolumn{2}{|c|}{ Table 1. Clinical Features (n=50) } \\
\hline
\end{tabular}




\begin{tabular}{|c|c|c|c|c|c|}
\hline $\begin{array}{c}\text { Clinical Types } \\
\text { of Leprosy }\end{array}$ & TT & BT & BB & BL & LL \\
\hline Number of patients & $\begin{array}{c}1 \\
(2 \%)\end{array}$ & $\begin{array}{c}24 \\
(48 \%)\end{array}$ & $\begin{array}{c}1 \\
(2 \%)\end{array}$ & $\begin{array}{c}14 \\
(28 \%)\end{array}$ & $\begin{array}{c}9 \\
(18 \%)\end{array}$ \\
\hline Bacterial Index & \multicolumn{5}{|c|}{ Highest BI in AFB Positive } \\
\hline BI-0 & 1 & 24 & 0 & 12 & 3 \\
\hline BI-1+ & & & 1 & & \\
\hline BI-2+ & & & & & \\
\hline BI-3+ & & & & 2 & 1 \\
\hline BI-4+ & & & & & 2 \\
\hline BI-5+ & & & & & \\
\hline BI-6+ & & & & & 3 \\
\hline Table 2. Performance of SSS for BI with RJ Clinical Types \\
\hline
\end{tabular}

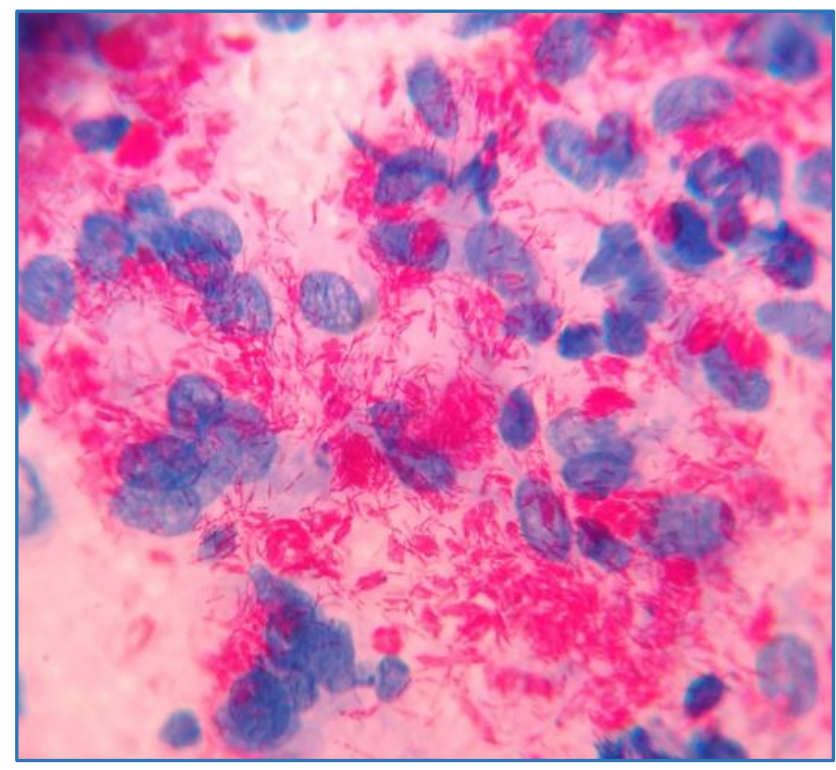

Figure 1. AFB in SSS

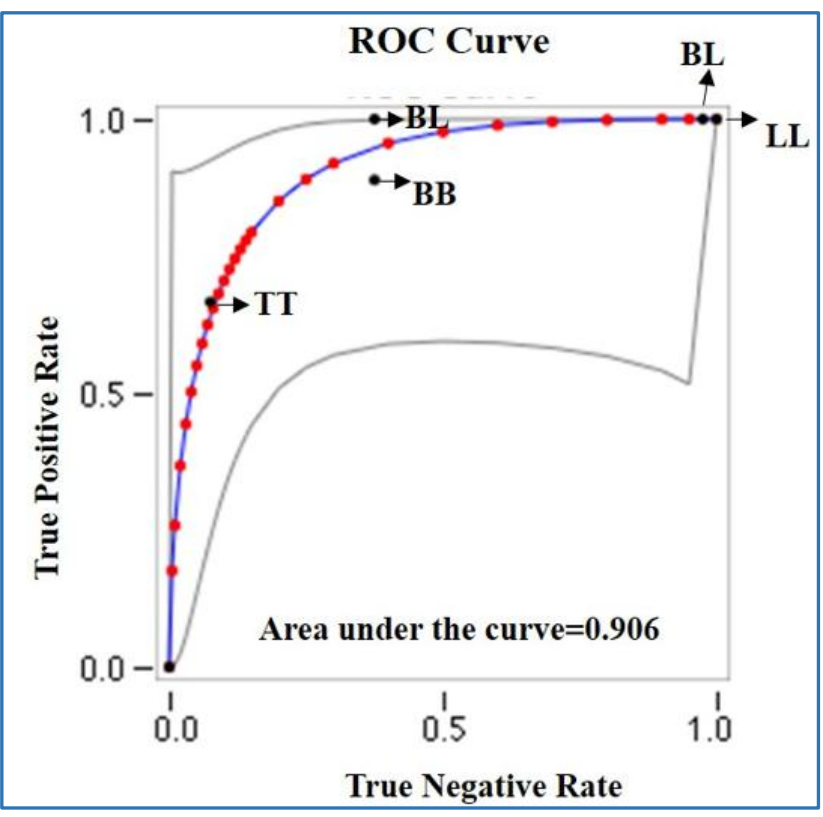

Figure 2. ROC Curve of SSS with RJ Classification Smooth Line above and below Dotted ROC Curve: 95\% Confidence Interval of the ROC Curve.

\begin{tabular}{|c|c|c|c|}
\hline \multirow{2}{*}{ SSS } & \multicolumn{2}{|c|}{ WHO Classification } & \multirow{2}{*}{ Total } \\
\cline { 2 - 3 } & Positive & Negative & \\
\hline Positive & $9(18 \%)$ & $0(0 \%)$ & $9(18 \%)$ \\
\hline Negative & $32(64 \%)$ & $9(18 \%)$ & $41(82 \%)$ \\
\hline Total & $\mathbf{4 1}$ & $\mathbf{9}$ & $\mathbf{5 0}(100 \%)$ \\
\hline \multicolumn{3}{|c|}{ Table 3. Diagnosis of MB Leprosy through } \\
SSS and WHO Classification; $\boldsymbol{n}=\mathbf{5 0}$ \\
\hline
\end{tabular}

\section{DISCUSSION}

The present national strategy of leprosy control is to sustain quality leprosy services by early detection of new cases and timely completion of treatment. Clinical signs and bacilloscopy (AFB) of skin smears are the conventional tools for the detection of leprosy patients. Therefore, the present study was carried on 50 untreated patients to see the clinical profile of new leprosy cases attending this tertiary centre and determine the significance of SSS microscopy in establishing the diagnosis of leprosy.

In the present study, mean age of presentation was 44 which is similar to studies by other authors. ${ }^{12,13}$ This older age of presentation may be explained by the long incubation period of the disease. History of contact with the leprosy patient was noted in 11 (22\%), a comparable finding to $20 \%$ as reported by R Dayal. ${ }^{14}$ There were total $3(6 \%)$ patients of paediatric age group with none of them having family history of leprosy. This shows that there is still continuous transmission of disease, and likelihoods of acquiring the infection in children outside the family is persistently high. ${ }^{15}$

Only skin lesions were seen in $12 \%$ of the patients, while $88 \%$ of the patients had both skin lesions and nerve thickening which is similar to the findings of a study conducted by Dayal et al. ${ }^{14}$ Most common skin lesions in present study was plaque followed by macule. These type of skin manifestations correlates with the study performed by Manandhar et al. ${ }^{16}$ Ulnar nerve (55\%) was the most common clinically thickened peripheral nerves in leprosy in present study, a comparable result to that seen in a study from India with involvement of same nerve being commonest (55\%). ${ }^{17}$ The most predominant clinical subtype was BT (48\%) which shows that cases are being reported at initial stage of disease for diagnosis and treatment. Another study from Nepal ${ }^{16}$ reported similar trend of early cases (TT) being reported which is an optimistic sign in this maintenance phase of leprosy elimination. All the paediatric leprosy cases of BT variant in our study is comparable to the findings of other childhood leprosy study. ${ }^{18}$ As leprosy is a disabling disease, $32 \%$ cases from our study also presented with disabilities with $20 \%$ grade 1 and $12 \%$ grade 2 deformity. This burden of leprosy disabilities reported from this hospital might be due to our setup being a tertiary centre, all the cases with problem from this eastern region are expected to be referred here. The proportion of grade 2 deformity of our study is lower than another prospective clinico-bacteriological study on newly diagnosed leprosy from India who have reported visible grade 2 deformities in $22 \%$ patients. ${ }^{17}$

SSS has the advantage of being easily performed, cost effective and almost $100 \%$ specific as it directly demonstrates the bacilli in the smear. But this laboratory test suffers from low sensitivity varying from $10-50 \% .{ }^{3}$ The results of this study revealed that SSS was positive in $18 \%$ patients with clinically diagnosed leprosy with $67 \%$ of LL and $14 \%$ of BL patients. Several studies have reported similar SSS 
sensitivities. In a study by Kamal et al, ${ }^{19} 20 \%$ cases were skin smear positive with $44 \%$ positivity in BL/LL variety. Similar rate of positivity of SSS was observed by Dayal et al ${ }^{14}$ with only $10 \%$ positivity out of total cases and that of BL variety. The sensitivity of SSS is affected by the reliability of the technique of taking smear, staining, and interpreting the slide which can be improved by regular quality control and regular training and supervision of laboratory staff. Literatures also have mentioned low sensitivity of SSS when compared to specificity.5,20 As our study showed the AUC of SSS to be 0.906, this indicates this method to be a good diagnostic tool. ${ }^{21}$

SSS detects the most infectious patients (MB type), 22\% in this study, which with timely initiation of treatment will prevent from consequent complications and horizontal transmission. Sensitivity of SSS reported was quite high in the study conducted at Kolkata in which $59.8 \%$ of MB type and $1.8 \%$ of $\mathrm{PB}$ type was positive. ${ }^{22}$ All negative results in $\mathrm{PB}$ cases as observed in our study were comparable to above study which can be explained by the scarcity of AFB in skin tissues in this spectrum.

\section{CONCLUSION}

Cases of BT leprosy are predominant. Presence of leprosy in paediatric age group indicates continued transmission. Notable disabilities 16 (32\%) were observed in our study. Although the slit-skin smear has low sensitivity, AUC of SSS was 0.906 indicating it being a good diagnostic tool. Being a simple and rapid method with high specificity, SSS can be used to confirm the diagnosis in clinically suspected patients of leprosy.

\section{REFERENCES}

[1] Leprosy Control Division. Department of health services, government of Nepal ministry of health and population. Kathmandu: Leprosy Control Division. Available:dohs.gov.np/divisions/leprosy-controlprogram.

[2] Diagnosis and classification of leprosy. International Journal Of Leprosy 2002;70 (1):S23-31.

[3] Ridley DS, Jopling WH. Classification of leprosy according to immunity-a five group system. Int J Lep Other Mycobact Dis 1966;34 (3):255-73.

[4] World health organization. Expert committee on leprosy: $6^{\text {th }}$ report. World Health Organ Tech Rep Ser. 1988;768:1-51. Available: whqlibdoc.who.int/trs/WHO_TRS_768.pdf.

[5] Report of the international leprosy association technical foum. 25-28 February 2002. Paris, France. Lepr Rev 2002;73:S3-61.

[6] Sehgal VN, Joginder. Slit-skin smear in leprosy. Int J Dermatol 1990;29 (1):9-16.

[7] World Health Organization. Expert committee on leprosy: $7^{\text {th }}$ report. World Health Organ Tech Rep Ser 1998;874:1-43.
[8] Mahajan VK. Slit-skin smear in leprosy: lest we forget it. Indian J Lepr 2013;85 (4):177-83.

[9] Job CK, Ponnaiya J. Laboratory diagnosis: In: Kar HK, Kumar B, (eds). LAL textbook of leprosy. New Delhi, Jaypee Brothers Medical Publishers (P) Ltd 2010:1768.

[10] Ridley DS. Bacterial indices. In: Leprosy in theory and practice. Cochrane RG, Davey TF, (eds). John Wright and Sons Ltd, Bristol 1964:620-2.

[11] Eng J. ROC analysis: web-based calculator for ROC curves. Baltimore: Johns Hopkins University. Available from: http://www.jrocfit.org.

[12] Robertson LM, Nicholls PG, Butlin R. Delay in presentation and start of treatment in leprosy: experience in an out-patient clinic in Nepal. Lepr Rev 2000;71 (4):511-6.

[13] Brakel VWH, Khawas IB, Lucas SB. Reaction in leprosy: an epidemiological study of 386 patient in west Nepal. Lepr Rev 1994;65 (3):190-203.

[14] Dayal R, Singh SP, Mathur PP, et al. Diagnostic value of in situ polymerase chain reaction in leprosy. Indian J pediatr 2005;72:1043-5.

[15] Singh I, Lavania M, Nigam A, et al. Symposium on emerging needs in leprosy research in the post elimination era: the leprosy mission trust India. Lepr Rev 2016;87 (1):132-43.

[16] Manandhar U, Adhikari RC, Sayami G. Clinicohistopathological correlation of skin biopsies in leprosy. Journal of Pathology of Nepal 2013;3 (6):4528.

[17] Sarkar K, Sarkar S, Pramanik N, et al. Clinicobacteriological study of leprosy- a profile from a tertiary care centre of eastern India. Research Chronicle in health sciences 2015;1 (5):246-50.

[18] Mohammed S, Khan MP, Aakurati P, et al. Epidemiological and clinical study of childhood Hansen's in a tertiary care hospital. Journal of Evolution of Medical and Dental Sciences 2015;4 (84):14716-20.

[19] Kamal R, Natrajan M, Katoch K, et al. Evaluation of diagnostic role of in situ PCR on slit-skin smears in pediatric leprosy. Indian J Lepr 2010;82 (4):195-200.

[20] Rao PN. Recent advances in the control programs and therapy of leprosy. Indian J Dermatol Venereol Leprol 2004;70 (5):269-76.

[21] Tape TG. Interpreting diagnostic tests. University of Nebraska medical center. Available: gim.unmc.edu /dxtests/roc2.htm.

[22] Banerjee S, Biswas N, Das KN, et al. Diagnosing leprosy: revisiting the role of the slit-skin smear with critical analysis of the applicability of polymerase chain reaction in diagnosis. Int J Dermatol 2011;50 (12):1522-7. 